\title{
Rapid cholesterol nucleation time and cholesterol gall stone formation after subtotal or total colectomy in humans
}

\author{
I Makino, K Chijiiwa, H Higashijima, S Nakahara, M Kishinaka, S Kuroki, R Mibu
}

\begin{abstract}
Changes in biliary lipid composition, $\mathbf{p H}$, ionised calcium, total and unconjugated bilirubin, and cholesterol nucleation time of gall bladder bile samples were examined in six patients who had undergone subtotal or total colectomy between five months and seven years previously, and values were compared with those in control patients with no gall stones. The colectomy group mainly comprised patients with ulcerative colitis and familial adenomatosis coli, in whom only a short length of the terminal ileum (mean (SEM) $2.25(0.57) \mathrm{cm})$ had been resected. The reconstruction procedures were ileoanal anastomosis in two patients, terminal ileostomy in two, ileorectal anastomosis in one, and J shaped ileal pouch-anal anastomosis in one patient. The distributions of age, sex, and relative body weight were similar in the two groups. The gall bladder bile was lithogenic in the post colectomy group - these patients had a significantly increased cholesterol saturation index $(p<0.01)$ and rapid cholesterol nucleation time $(p<0.05)$ compared with the control group. A significant increase in the molar percentage of cholesterol and a decrease in that of total bile acid associated with significantly decreased secondary bile acids $(p<0.05)$ were observed in the post colectomy group. Gall stones formed in two of six patients after colectomy were cholesterol stones containing more than $80 \%$ cholesterol by dry weight. Total and unconjugated bilirubin, $\mathrm{pH}$, and ionised calcium values were similar in the two groups. The results indicate that after total or subtotal colectomy the composition of gall bladder bile increases the risk of cholesterol gall stone formation.

(Gut 1994; 35: 1760-1764)
\end{abstract}

TABLE I Clinical profile of the patients who had undergone colectomy

\begin{tabular}{|c|c|c|c|c|c|c|c|c|}
\hline Patient & $\begin{array}{l}\text { Age } \\
(y)\end{array}$ & Sex & $\begin{array}{l}\text { Relative body } \\
\text { weight }(\%)^{\star}\end{array}$ & $\begin{array}{l}\text { Primary } \\
\text { disease }\end{array}$ & Colectomy & Reconstruction & $\begin{array}{l}\text { Time after } \\
\text { colectomy }\end{array}$ & Remarks \\
\hline $\begin{array}{l}1 \\
2 \\
3 \\
4\end{array}$ & $\begin{array}{l}19 \\
56 \\
26 \\
46\end{array}$ & $\begin{array}{l}F \\
F \\
M \\
F\end{array}$ & $\begin{array}{r}134 \cdot 2 \\
90 \cdot 0 \\
89 \cdot 2 \\
84 \cdot 5\end{array}$ & $\begin{array}{l}\text { FAC } \\
\text { UC } \\
\text { UC } \\
\text { Multiple } \\
\text { ulcer }\end{array}$ & $\begin{array}{l}\text { Total } \\
\text { Total } \\
\text { Subtotal } \\
\text { Subtotal }\end{array}$ & $\begin{array}{l}\text { IAA } \\
\text { JIPA } \\
\text { Ileostomy } \\
\text { IRA }\end{array}$ & $\begin{array}{l}4 \text { y } 3 \mathrm{mth} \\
4 \text { y } 9 \mathrm{mth} \\
1 \text { y } \\
4 \text { y } 6 \mathrm{mth}\end{array}$ & $\begin{array}{l}\text { Gall stone } \\
\text { Gall stone }\end{array}$ \\
\hline 5 & 67 & $\mathbf{F}$ & $79 \cdot 5$ & $\mathrm{UC}$ & Subtotal & Ileostomy & $5 \mathrm{mth}$ & $\begin{array}{l}\text { Gall bladder } \\
\text { sludge }\end{array}$ \\
\hline 6 & 37 & $\mathbf{M}$ & $110 \cdot 2$ & FAC & Total & IAA & $7 y$ & \\
\hline
\end{tabular}

$\star$ Calculated as body weight $(\mathrm{kg}) /\{$ height $(\mathrm{cm})-100\} \times 100$.

FAC $=$ familial adenomatosis coli; $\mathrm{UC}=$ ulcerative colitis; IAA=ileoanal anastomosis; IRA=ileorectal anastomosis; JIPA $=\mathrm{J}$ shaped ileal pouch-anal anastomosis.
Total or subtotal colectomy are the surgical treatments of choice for patients with ulcerative colitis or familial adenomatosis coli. The colon is the site where the primary bile acids are deconjugated and dehydroxylated by enzymes released from colonic bacteria and the secondary bile acids that are formed, deoxycholic acid and lithocholic acid, are mainly absorbed. ${ }^{1-3}$ Thus, the colon as well as the small intestine plays an important role in the enterohepatic circulation of bile acids.

One of the annoying complications after colectomy is gall stone disease. ${ }^{4}$ Changes in biliary lipids and bile acid composition after colectomy have been investigated in an animal model and in a human one. The increase in the cholesterol saturation index of gall bladder bile after total proctocolectomy with interposed jejunal segment as neorectum was reported in the canine model. ${ }^{5}$ Harvey et $a l^{6}$ recently showed an increased cholesterol saturation index and rapid cholesterol nucleation time of gall bladder bile similar to values from patients with cholesterol gall stones ${ }^{78}$ in patients with ulcerative colitis who had undergone colectomy. There is, however, a lack of detailed information about the kind of gall stones formed and changes in other bile components after total or subtotal colectomy in humans.

This study aimed to examine changes in biliary lipid composition, bilirubin, ionised calcium, and the nucleation time of gall bladder bile after human colectomy. In addition, gall stones formed after colectomy were chemically analysed.

\section{Methods}

\section{PATIENTS}

Post colectomy group

Six patients who had undergone elective colectomy participated in the study (Table I). There were four women and two men with a mean (SEM) age of $41.8(7 \cdot 4)$ years. Total colectomy had been performed in three patients and subtotal colectomy in the remainder. The mean (range) time since colectomy was 3.7 years ( 5 months to 7 years). Three patients had ulcerative colitis, two familial adenomatosis coli, and one patient had multiple colonic ulcer. In all six patients only very short lengths of the terminal ileum (less than $5 \mathrm{~cm}$, mean (SEM) $2 \cdot 25(0.57) \mathrm{cm}$ ) were resected. Reconstruction procedures after colectomy were ileoanal anastomosis in two; 
TABLE II Composition of gall bladder bile in patients with colectomy and control subjects

\begin{tabular}{|c|c|c|}
\hline & $\begin{array}{l}\text { Control patients } \\
(n=11)\end{array}$ & $\begin{array}{l}\text { Post colectomy } \\
\text { patients }(n=6)\end{array}$ \\
\hline $\begin{array}{l}\text { Total lipid (g/dl) } \\
\text { Cholesterol: }\end{array}$ & $12 \cdot 03(2 \cdot 16)$ & $11 \cdot 27(1 \cdot 47)$ \\
\hline $\begin{array}{l}(\mathrm{mM}) \\
(\mathrm{molar} \%)\end{array}$ & $\begin{array}{l}15 \cdot 64(3 \cdot 60) \\
(6 \cdot 27(0 \cdot 63))\end{array}$ & $\begin{array}{l}23.75(4 \cdot 13) \\
\left(11 \cdot 48(1.33)^{\star}\right)\end{array}$ \\
\hline $\begin{array}{l}\text { Total bile acid: } \\
(\mathrm{mM}) \\
(\mathrm{molar} \%)\end{array}$ & $\begin{array}{l}167 \cdot 56(28 \cdot 22) \\
(76 \cdot 8(1 \cdot 48))\end{array}$ & $\begin{array}{l}138.35(18.67) \\
\left(66.57(2.54)^{\star}\right)\end{array}$ \\
\hline $\begin{array}{l}\text { Phospholipid: } \\
\text { (Mm) } \\
\text { (molar \%) }\end{array}$ & $\begin{array}{c}41 \cdot 17(8 \cdot 45) \\
(16.93(0.99))\end{array}$ & $\begin{array}{c}45.95(6.88) \\
\left(21.95(1.38)^{\star}\right)\end{array}$ \\
\hline $\begin{array}{l}\text { Cholesterol saturation } \\
\text { index }\end{array}$ & $1 \cdot 04(0 \cdot 08)$ & $1.56(0.16)^{\star}$ \\
\hline $\begin{array}{l}\mathrm{pH} \\
\text { Ionised } \mathrm{Ca}(\mathrm{mM}) \\
\text { Total bilirubin }(\mathrm{mg} / \mathrm{ml}) \\
\text { Unconjugated bilirubin (\%) }\end{array}$ & $\begin{array}{l}7.22(0.16) \\
0.95(0.08) \\
3.12(0.54) \\
0.89(0.05)\end{array}$ & $\begin{array}{l}7 \cdot 30(0 \cdot 13) \\
1 \cdot 17(0 \cdot 17) \\
3 \cdot 01(0 \cdot 71) \\
1 \cdot 46(0 \cdot 48)\end{array}$ \\
\hline
\end{tabular}

*Significantly different from the control $(p<0.01)$.

ileostomy in two, ileorectal anastomosis in one; and $\mathrm{J}$ shaped ileal pouch-anal anastomosis in one patient. None of the patients had gall bladder disease at the time of colectomy: this had been confirmed by preoperative ultrasonography and intraoperative palpation of the gall bladder. Two of the six patients (patients 1 and 2) developed gall stone disease four months and 57 months respectively after colectomy and another patient (patient 5) had gall bladder sludge five months after colectomy (Table I). These patients underwent cholecystectomy. The other three patients underwent a second operation for closure of ileostomy with ileoanal anastomosis (patient 3), resection of minor ileocutaneous fistula after subtotal colectomy with ileorectal anastomosis (patient 4), and resection of duodenal tumour (patient 6).

\section{Gall stone free control group}

This group consisted of six men and five women with a mean (SEM) age of 54.6 (4.0) years. There were four patients with colon cancer, four with gastric cancer, two with pancreatic cancer, and one with pheochromocytoma of the adrenal gland. The absence of gall stone disease was confirmed by preoperative ultrasonography and intraoperative palpation of the gall bladder.

All the patients studied were eating a normal diet. They had no diseases affecting the

TABLE III Gall bladder bile acid composition (\%) in patients with colectomy and controls

\begin{tabular}{lcc}
\hline & $\begin{array}{l}\text { Control patients } \\
(n=11)\end{array}$ & $\begin{array}{l}\text { Post colectomy } \\
\text { patients }(n=6)\end{array}$ \\
\hline CA & $41.55(2 \cdot 71)$ & $61 \cdot 22(3.92)^{\star}$ \\
CDCA & $40.47(2 \cdot 26)$ & $38.37(3.73)$ \\
DCA & $13.10(3.40)$ & $0.03(0.03) \dagger$ \\
LDCA & $4.46(1.51)$ & $0.37(0 \cdot 22)$ \\
LCA & $0.45(0 \cdot 24)$ & ND \\
CDCDCA & $54.63(2.52)$ & $61 \cdot 25(3.89)$ \\
Primary bile acid & $45.37(2.52)$ & $38.75(3.89)$ \\
Secondary bile acid & $82.01(2.82)$ & $99.61(0.24)^{\star}$ \\
& $13.54(3.54)$ & $0.03(0.03) \dagger$
\end{tabular}

$\mathrm{CA}=$ cholic acid; $\mathrm{CDCA}=$ chenodeoxycholic acid; DCA=deoxycholic acid; UDCA = ursodeoxycholic acid; LCA = lithocholic acid; $N D=$ not detected; primary bile acid =CA + CDCA; secondary bile acid =DCA + LCA $\star$ Significantly different from the control $(p<0.01)$. †Significantly different from the control $(p<0.05)$. hepato-biliary system and their liver function tests were within the normal range. No significant differences were found in age, sex, and the relative body weight (colectomy $v$ control, $97.9 \% v 88.2 \%$ ) between the two groups. Informed consent was obtained from all patients before surgery. The study was approved by the senior staff committee of the department.

BILE SAMPLES

At the time of surgery and after an overnight fast, gall bladder bile was completely aspirated by needle to avoid stratification of bile, and care was taken to avoid contamination with blood. Fresh gall bladder bile samples thus obtained were kept in sterile test tubes at $37^{\circ} \mathrm{C}$ in the dark and were immediately subjected to determinations of $\mathrm{pH}$, ionised calcium, and total and free bilirubin. Bile samples $(3 \mathrm{ml})$ were ultracentrifuged at $37^{\circ} \mathrm{C}$ for two hours at $10^{5} \mathrm{~g}$ (55 P-72, Hitachi, Tokyo, Japan) and the isotropic bile samples obtained were used for the nucleation time study as described below. Part of the bile sample was stored at $-20^{\circ} \mathrm{C}$ for chemical analyses.

\section{BILE ANALYSIS}

The ionised calcium and $\mathrm{pH}$ of fresh gall bladder bile were determined using an automated analyser (CAI 101, Shimadzu, Kyoto, Japan). Concentrations of individual bile acids and cholesterol were simultaneously determined using gas-liquid chromatography (GC 15 A, Shimadzu, Kyoto, Japan, equipped with a fused silica column - HiCap-CBP1, 20 $\mathrm{m} \times 0.2 \mathrm{~mm} \mathrm{ID}$, Shimadzu, Kyoto, Japan) as previously reported. ${ }^{9}$ The total bile acid concentration was determined as the sum of the individual bile acids. Phospholipid was quantitated by the method of Bartlett. ${ }^{10}$ The cholesterol saturation index was calculated according to the critical table provided by Carey. ${ }^{11}$ Total bilirubin was determined as described by Michaelsson ${ }^{12}$ and the bilirubin fractions were analysed using high performance liquid chromatography (ALC/GP C 202, Waters, Milford, MA) according to the method of Spivak and Carey. ${ }^{13}$

\section{Gall stone analysis}

Gall stones obtained from two patients who had undergone colectomy were dried, weighed, crushed, and extracted with dimethylsulphoxide-acetone-1 $\mathrm{N} \mathrm{HCl}(90: 9: 1 \mathrm{v} / \mathrm{v} / \mathrm{v})$ and were subjected to the determination of cholesterol as previously reported. ${ }^{14}$

\section{NUCLEATION TIME}

The earliest time that cholesterol monohydrate crystals appeared in gall bladder bile was determined as previously described, ${ }^{7815}$ based on the method of Holan et al. ${ }^{16}$ After confirming the absence of cholesterol monohydrate crystals, isotropic bile samples were kept in sterile brown tubes under nitrogen at 


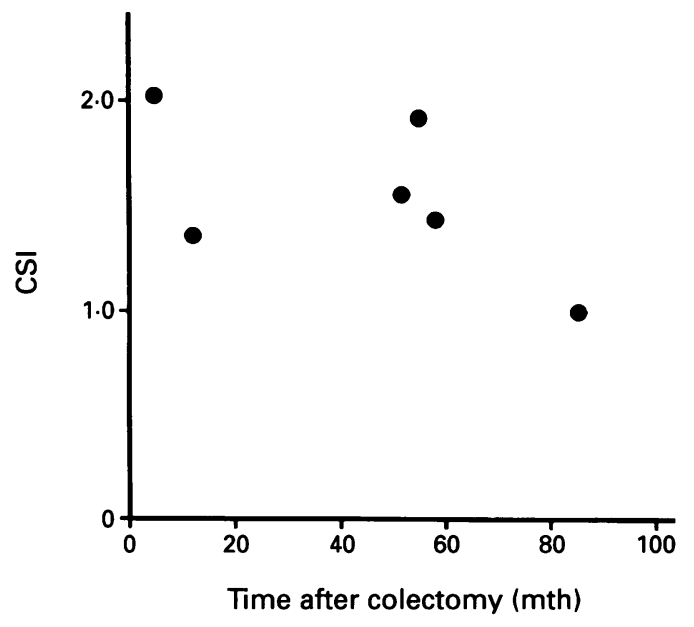

Figure 1: Cholesterol saturation index and time after colectomy. No significant correlation was observed between the cholesterol saturation index and the time after colectomy by the method of least squares $(r=0.57, p=0 \cdot 24)$.

$37^{\circ} \mathrm{C}$ in the dark without shaking and were examined daily over 21 days for the appearance of cholesterol monohydrate crystals using a polarised microscope (Nikon XTP-2, Tokyo, Japan). Where cholesterol crystals did not appear during the observation period, the nucleation time was recorded as 21 days.

\section{STATISTICAL ANALYSIS}

All data are given as mean (SEM). Statistical differences between the two groups were analysed by unpaired Student's $t$ test. The incidence of cholesterol monohydrate crystal nucleation was calculated by the Kaplan-Meier method and compared by the Mantel-Cox test. Correlation between the cholesterol saturation index and time after colectomy was examined by the method of least squares.

\section{Results}

GALLBLADDER BILE COMPOSITION

The biliary lipid composition and cholesterol saturation index are shown in Table II. The cholesterol saturation index of the gall bladder bile in the colectomy group was significantly higher than that in the gall stone free control

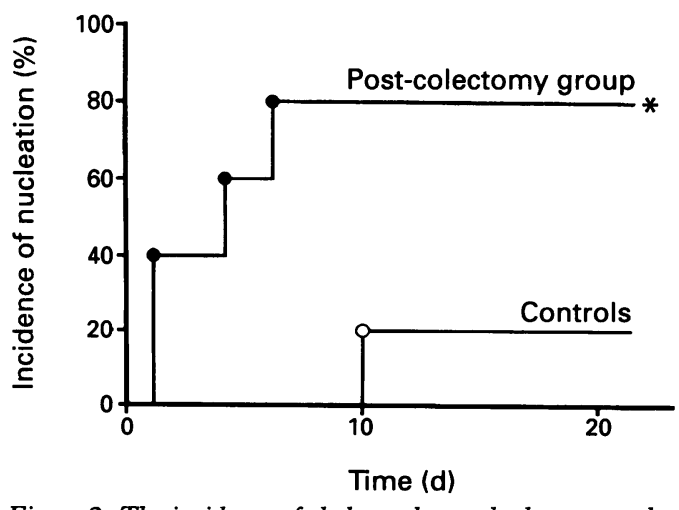

Figure 2: The incidence of cholesterol monohydrate crystal nucleation of gall bladder bile in the gall stone free control $(n=5)$ and post colectomy $(n=5)$ groups calculated by the Kaplan-Mieer method. * Significantly different $(p<0 \cdot 05)$ from the control group by the Mantel-Cox test. group $(\mathrm{p}<0 \cdot 01)$. The total lipid concentration was similar in the two groups. The concentration of biliary cholesterol was higher in the colectomy group than in the controls, although the difference was not statistically significant. The molar percentage of cholesterol, however, was significantly $(\mathrm{p}<0.01)$ higher in the colectomy group. The total bile acid concentration was lower in the colectomy group but this was not statistically significant. The molar percentage of total bile acid was significantly $(p<0.01)$ decreased in the colectomy group. The molar percentage of phospholipid was significantly higher in the colectomy group. The ionised calcium, $\mathrm{pH}$, and total bilirubin concentration were similar in the two groups. The proportion of unconjugated bilirubin was higher in the colectomy group than the controls, but there was no statistically significant difference.

The gall bladder bile acid composition is shown in Table III. The cholic acid level was significantly higher $(p<0.01)$ and the deoxycholic acid value was significantly lower $(p<0.05)$ (in molar percentage) in the colectomy group. The molar percentage of chenodeoxycholic acid was similar in the two groups. The sum of cholic acid plus its metabolite (deoxycholic acid) and that of chenodeoxycholic acid plus its metabolites (lithocholic acid and ursodeoxycholic acid) were not significantly different between the two groups. Primary bile acid was significantly higher in the controls $(p<0 \cdot 01)$. Secondary bile acids were absent or only present as traces in the colectomy group.

CHOLESTEROL SATURATION INDEX AND TIME AFTER COLECTOMY (FIG 1)

An obviously high cholesterol saturation index $(2.03)$ was observed as early as five months after colectomy (patient 5). Most patients in the post colectomy group showed increased cholesterol saturation index within 5 to 57 months after colectomy. One patient with familial adenomatosis coli and ileoanal anastomosis (patient 6 ) showed a relatively low cholesterol saturation index. No significant correlation was obsetved between the cholesterol saturation index and the time after colectomy $(r=0 \cdot 57, p=0 \cdot 24)$.

CHOLESTEROL NUCLEATION TIME (FIG 2)

In the colectomy group, cholesterol monohydrate crystals appeared within three days in four of five patients. In contrast, cholesterol crystals did not appear during the observation period in four of five control patients. The colectomy patients had a significantly faster nucleation time than the controls $(6.4$ (3.8) $v$ $18 \cdot 8(2 \cdot 2)$ days, $\mathrm{p}<0 \cdot 05)$.

ANALYSIS OF GALL STONES OF THE COLECTOMY GROUP

Gall stones were cholesterol stones by gross inspection. Chemical analysis showed that gall stones from patients 1 and 2 contained 
$100 \%$ and $80 \%$ cholesterol by dry weight, respectively.

\section{Discussion}

The current study showed that the biliary lipid composition, cholesterol saturation index, and nucleation time in patients after colectomy resembled values in patients with cholesterol gall stones. ${ }^{781516}$ These changes are in good agreement with the fact that the gall stones formed in the colectomy group were confirmed by chemical analysis to be cholesterol gall stones.

The present results are consistent with those of Harvey et al $^{6}$ who reported an increased cholesterol saturation index and rapid nucleation time after colectomy in patients with ulcerative colitis. Nearly half of their control subjects had a nucleation time of less than six days, whereas cholesterol crystals did not appear within 21 days in most of our control patients. The difference may be due to the fact that patients with ulcerative colitis served as the controls in the study of Harvey et al. Increased excretion of bile acids in ulcerative colitis patients has been reported, even in remission, ${ }^{17}$ so the bile acid metabolism might have been changed in their controls.

In the present study, the molar percentage of bile acid decreased while cholesterol and phospholipids increased. The increased cholesterol saturation index after colectomy was a result of changes in the biliary lipids (Table II). Bile acid metabolism after colectomy has been reported by several authors. ${ }^{18-22}$ An increased faecal bile acid excretion has been reported after colectomy with continent ileostomy, conventional ileostomy, or ileal pouch-anal anastomosis. ${ }^{19-21}$ Salemans et al recently investigated postprandial serum bile acid levels in colectomy patients with ileal pouch-anal anastomosis and suggested that bile acid malabsorption occurs after colectomy. ${ }^{22}$ Thus, the colectomy patients in the present study may have had malabsorption of bile acids.

Biliary bile acid secretion is regulated by its pool size 2324 and the turnover rate of the enterohepatic circulation. ${ }^{25}$ Rutgeerts et al ${ }^{26}$ showed that the supersaturated bile is formed as a result of the more reduced biliary output of bile acids than of cholesterol in patients who underwent partial ileocolonic resection. They suggested that the partial interruption of the enterohepatic circulation of bile acids reduces the size of the bile acid pool and decreases bile acid secretion. In animal experiments, relatively decreased bile acid secretion has also been reported when enterohepatic circulation has been interrupted. ${ }^{27} 28$ Although a very limited length of terminal ileum was resected in our patients with colectomy, partial interruption of the enterohepatic circulation of bile acids might be present.

Cholesterol absorption is carried out in the upper third of the small intestine and is disturbed only when bile acid absorption is severely affected. ${ }^{29}$ The increased proportion of cholesterol in the present study is probably secondary to the decreased bile acid secretion as described above. Thus, we consider that the bile acid malabsorption resulted in the altered biliary lipid composition and the increased lithogenecity in patients with total or subtotal colectomy.

Gall bladder bile acid composition was also changed in patients with colectomy. The appreciable decrease in deoxycholic acid may be the direct effect of colectomy because secondary bile acids are formed and absorbed in the colon. ${ }^{1-3}$ This change is in good agreement with previous studies showing a reduced excretion of secondary bile acids in the ileal effluent in patients with ileostomy. ${ }^{18} 1930$ The significantly increased cholic acid concentration in gall bladder bile also suggests that less cholic acid is metabolised further to deoxycholic acid in the colectomy group. It is thus probable that the increased proportion of biliary cholic acid and the decreased proportion of deoxycholic acid may result from reductions in both the $7 \alpha$-dehydroxylation of cholic acid and the passive absorption of deoxycholic acid in the patients with colectomy. A shorter intestinal transit time ${ }^{19}$ and changes in the intestinal microflora may be responsible for the reductions.

The other important finding in this study is the chemical analysis of gall stones obtained from patients with colectomy, since there is no published report of this. The gall stones formed were cholesterol stones. Lithogenic bile appeared soon after colectomy and no correlation was found between the cholesterol saturation index and the time after colectomy (Fig 1). The results suggest that the increased risk of cholesterol gall stone formation occurs shortly after colectomy and persists.

The number of patients with colectomy is small and they were a heterogeneous group with regard to the original disease and the reconstruction procedure. Most of these patients had a high cholesterol saturation index and a rapid nucleation time of gall bladder bile irrespective of their original disease or the reconstruction procedure. The biliary bile acid composition was also very similar in these patients. These results suggest that colectomy itself changes the bile acid metabolism, leading to the increased lithogenecity of gall bladder bile.

Subtotal or total colectomy had no effect on the $\mathrm{pH}$, ionised calcium, and total and unconjugated bilirubin of gall bladder bile, which are responsible for pigment gall stone formation. Gall stones formed in the colectomy patients were shown by chemical analysis to consist mainly of cholesterol. The results again support the suggestion that gall bladder bile after colectomy is in a condition to form cholesterol gall stones.

In conclusion, cholesterol gall stones and lithogenic gall bladder bile characterised by an increased cholesterol saturation index and rapid nucleation time were formed in patients after subtotal or total colectomy. Prophylactic cholecystectomy or the administration of cholelitholytic agents may prevent cholesterol 
gall stone disease after subtotal or total colectomy.

This work was supported in part by a grant in aid (no 03670633 $\mathrm{K}$ Chijiiwa) from the Ministry of Education, Science and Culture, Japan.

1 Marcus SN, Heaton KW. Deoxycholic acid and the pathogenesis of gall stones. Gut 1988; 29: 522-33.

Samuel P, Saypol GM, Meilman E, Mosbach EH, Chafizadeh $M$. Absorption of bile acids from the large bowel in man. $f$ Clin Invest 1968; 47: 2070-8.

3 Fujii T, Yanagisawa J, Nakayama F. Absorption of bile acids in dogs as determined by portal blood sampling: evidence for colonic absorption of bile acid conjugates. Digestion 1988; 41: 207-14.

4 Kurchin A, Ray JE, Bluth EI, Merritt CRB, Gathright JB, Pehrsson BF, Ferrari BT. Cholelithiasis in ileostomy patients. Dis Colon Rectum 1984; 27: 585-8.

patients. Dis Colon Rectum 1984; 27: 585-8.
5 Itoh H, Nakahara S, Nakamura K, Ikeda S, Mibu R, Osato K, Nakayama F. Bile composition after total proctocolectomy with interposed jejunal segment as neorectum. Dis Colon Rectum 1989; 32: 711-5.

Harvey PRC, McLeod RS, Cohen Z, Strasberg SM. Effec of colectomy on bile composition, cholesterol crystal formation, and gallstones in patients with ulcerative colitis. Ann Surg 1991; 214: 396-402.

7 Chijiiwa K, Hirota I, Noshiro $\mathrm{H}$. High vesicular cholesterol and protein in bile are associated with formation of cholesterol but not pigment gallstones. Dig Dis $S c i 1993$ 38: $161-6$.

8 Hirota I, Chijiiwa K, Noshiro H, Nakayama F. Effect of chenodeoxycholate and ursodeoxycholate on nucleation time in human gallbladder bile. Gastroenterology 1992; time in human

9 Chijiiwa K, Nakayama F. Simultaneous microanalysis of bile acids and cholesterol in bile by glass capillary colum gas chromatography. $\mathcal{F}$ Chromatogr 1988; 431: 17-25.

10 Barlett GR. Phosphorus assay in column chromatography. f Biol Chem 1959; 234: 466-8.

11 Carey MC. Critical tables for calculating the cholestero saturation of native bile. 7 Lipid Res 1978; 19: 945-55.

12 Michaelsson $M$. Bilirubin determination in serum and urine. Scand f Clin Lab Invest 1961; 13 (suppl 56): 1-80.

13 Spivak W, Carey MC. Reverse-phase h.p.l.c. separation, quantification and preparation of bilirubin and its conjugates from native bile. Biochem $f$ 1985; 225: 782-805.

14 Yamashita N, Yanagisawa J, Nakayama F. Composition of intrahepatic calculi. Dig Dis Sci 1988; 33: 449-53.

15 Gollish SH, Burnstein MJ, Ilson RG, Petrunka CN, Strasberg SM. Nucleation of cholesterol monohydrate crystals from hepatic and gallbladder bile of patients with cholesterol gall stones. Gut 1983; 24: 836-44.

16 Holan KR, Holzbach RT, Hermann RE, Cooperman AM
Claffey WJ. Nucleation time: a key factor in the pathogenesis of cholesterol gallstone disease. Gastroenterology 1979; 77: $611-7$.

17 Ejederhamn J, Rafter JJ, Strandvik B. Faecal bile acid excretion in children with inflammatory bowel disease. Gut 1991; 32: 1346-51.

18 Kay RM, Cohen Z, Siu KP, Petrunka CN, Strasberg SM Ileal excretion and bacterial modification of bile acids and cholesterol in patients with continent ileostomy. Gut $1979 ; 21: 128-32$

19 Pedersen BH, Simonsen L, Hansen LK, Giese B, Justesen $\mathrm{T}$, Tougaard L, Binder V. Bile acid malabsorption in patients with an ileum reservoir with a long efferent leg to an anal anastomosis. Scand $\mathcal{F}$ Gastroenterol 1985; 20: 995-1000.

20 Hylander E, Ladefoged K, Nielsen ML, Nielsen OV, Thale $M$, Jarnum $S$. Excretion, deconjugation, and absorption of bile acids after colectomy for ulcerative colitis. Scand $\mathcal{F}$ Gastroenterol 1986; 21: 1137-43.

21 Natori $\mathrm{H}$, Utsunomiya J, Yamamura $T$, Benno $Y$, Uchida $\mathrm{K}$. Fecal and stomal bile acid composition after ileostomy or ileoanal anastomosis in patients with chronic ulcerative colitis and adenomatosis coli. Gastroenterology 1992; 102: colitis and $1278-88$.

22 Salemans JMJI, Nagengast FM, Tagerman A, Van Schaik A, De Haan AFJ, Jansen JBMJ. Postprandial conjugate and unconjugated serum bile acid levels after proctocolectomy with ileal pouch-anal anastomosis. Scand $f$ Gastroenterol 1993; 28: 786-90.

23 Shaffer EA, Small DM. Biliary lipid secretion in cholestero gallstone disease: the effect of cholecystectomy and obesity. 7 Clin Invest 1977; 59: 828-40.

24 Rutgeerts P, Ghoos Y, Vantrappen G. The enterohepatic circulation of bile acids during continuous liquid formula perfusion of the duodenum. F Lipid Res 1983; 24: 614-9.

25 Northfield TC, Hofmann AF. Biliary lipid output during three meals and an overnight fast. I Relationship to bile acid pool size and cholesterol saturation of bile in acillstone and control subjects. Gut 1975; 16: 1-17.

26 Rutseerts $\mathrm{P}$, Ghoos Y, Vantrappen G. Effects of partial ileoRutgeerts $P$, Ghoos Y, Vantrappen G. Effects of partial ileo-
colectomy and Crohn's disease on biliary lipid secretion. colectomy and Crohn's disease

27 Dowling RH, Mack E, Small DM. Effects of controlled interruption of the enterohepatic circulation of bile salts by biliary diversion and by ileal resection on bile salt secretion, synthesis, and pool size in the rhesus monkey. f Clin Invest 1970; 49: 232-42.

28 Dowling RH, Mack E, Small DM. Biliary lipid secretion and bile composition after acute and chronic interruption of the enterohepatic circulation in the rhesus monkey. 7 Clin Invest 1971; 50: 1917-26.

29 Färkkilä MA. Biliary cholesterol and lithogeneity of bile in patients after ileal resection. Surgery 1988; 104: 18-25.
Stiehl A, Raedsch R, Rudolph G. Ileal excretion of bile acids: comparison with biliary bile composition and effect of ursodeoxycholic acid treatment. Gastroenterology 1988 94: $1201-6$.

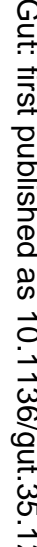 \\ ने

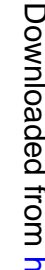

